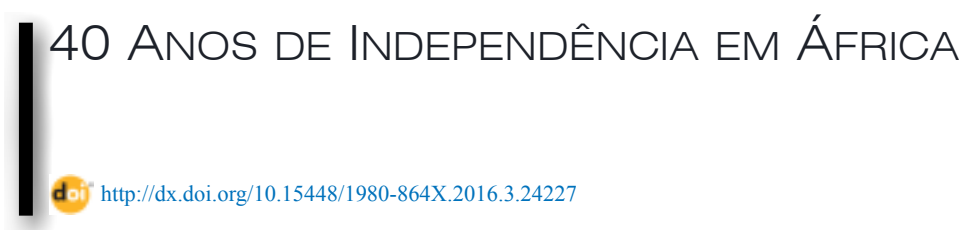

\title{
O projeto nacional na Guiné-Bissau: uma avaliação*
}

\author{
The national project in Guiné-Bissau: an evaluation \\ El proyecto nacional en Guiné-Bissau: una evaluación \\ Wilson Trajano Filho**
}

\begin{abstract}
Resumo: O texto indaga o quanto os projetos e sonhos caros aos nacionalistas guineenses foram realmente alcançados e implementados passados mais de 40 anos da independência do país. Passando em revista as instabilidades políticas e os falhanços econômicos ocorridos após a independência da Guiné-Bissau, a análise conclui de modo otimista ressaltando que apesar das dificuldades encontradas no processo de formação estatal, o projeto crioulo de construção nacional avança.
\end{abstract}

Palavras-chave: Guiné-Bissau; projeto nacional; identidade; projeto crioulo

\begin{abstract}
This paper examines how far political projects and aspirations dear to Guinean nationalists were actually achieved and implemented after 40 years of Guinea-Bissau's independence. Reviewing the political instabilities and economic failures that have taken place after the independence, the general conclusion is optimistic. It argues that despite the enormous challenges related to the process of state formation, the nationbuilding process headed by Guinean Creole Society has unexpectedly advanced.
\end{abstract}

Keywords: Guinea-Bissau; national project; identity; creole project

resumen: El texto se pregunta o cuanto los proyectos y sueños preciados a los nacionalistas de Guinea-Bissau se lograron e fueran en realidad implementados después de más de 40 años de su independencia. Analizando las inestabilidades políticas y fallas económicas ocurridos después de la independencia de Guinea-Bissau en la vida, el análisis concluye con optimismo resaltando que a pesar de las dificultades encontradas en el proceso de formación del Estado, el proyecto de construcción nacional avanza.

Palabras clave: Guinea Bissau; proyecto nacional; identidad; proyecto criollo

\footnotetext{
* Agradeço aos dois pareceristas anônimos, um pelo apoio e outro pela crítica severa, que tento, na medida do possível, replicar. Desnecessário dizer que sou inteiramente responsável pelas falhas, imprecisões e problemas que continuam a viver no trabalho.

** Professor do departamento de Antropologia da Universidade de Brasília. <wilson.trajanofilho@ gmail.com $><$ dados biográficos/biographic data $>$
} 
Passados 43 anos da declaração unilateral de independência da Guiné-Bissau feita pelo Partido Africano da Independência da Guiné e Cabo Verde (PAIGC) em 1973 e 42 anos do seu reconhecimento por Portugal e grande parte da comunidade internacional, estamos agora numa boa distância crítica para indagar o quanto os projetos e sonhos caros aos nacionalistas que combateram os tugas foram realmente alcançados e implementados. Não se trata de uma indagação inocente, despojada de riscos e de armadilhas. Qualquer resposta com alguma dimensão de razoabilidade passa necessariamente pelos filtros e pelos enquadramentos de hipóteses subjacentes, na maior parte das vezes implícitas e, com alguma recorrência, furtivas. Em primeiro lugar, chamo atenção para o fato de que estou me referindo a projetos e sonhos, e não a coisas acabadas, manuseáveis e sólidas, como as instituições. Mais: insisto na forma plural, o que pressupõe algum nível de competição e de disputa, de tensão e de conflito. Mas como se trata de projetos e sonhos, estamos em pleno universo das acomodações, alterações e desfigurações por meio das quais os contornos podem se alterar drasticamente, sem que a substância dura que reside em seus corações seja minimamente perturbada. Outras vezes, o caroço apodrece e decai sem que tal declínio contamine imediatamente a polpa que, para muitos, continua carnuda, atraente e desejosa. Em segundo lugar, alcançar e implementar o que quer que seja demanda de quem observa e avalia alguma unidade de medida. Sabemos todos que, projetos, por mais bem executados que sejam, sempre deixam zonas de sombra, dimensões inconclusas, partes mal-acabadas e recantos que carecem de retoques. E os sonhos? $\mathrm{Ah}$, estes esvanecem no ar e, como as nuvens, mudam inconstantes e voluntariosos de figura.

Inicio, então, expondo, o mais claramente possível, as hipóteses de trabalho que me orientam acerca dos projetos e sonhos dos nacionalistas, reconhecendo de partida a heterogeneidade de ambos (dos projetos bem como dos nacionalistas). Quando menciono projetos e sonhos caros aos nacionalistas, estou pensando num projeto crioulo, elaborado no seio da sociedade crioula guineense que, no final dos anos de 1950, não tinha outra opção razoável para o seu devir que não fosse o da GuinéBissau enquanto estado-nação. Todo o resto seria, para ela, reprodução da subordinação. Adiantando o arrazoado que se seguirá, argumento que a sociedade crioula da Guiné-Bissau sempre foi polimórfica, assumindo formas variadas ao longo do tempo bem como a cada momento em que é escrutinada. Este é o ponto de vista que tem sustentado todo o meu investimento de pesquisa na Guiné-Bissau e toda uma série de trabalhos 
que tenho escrito (TRAJANO FILHO, 1998, 2005a, 2005b, 2010). No final dos anos 1950, com efervescência exitosa dos nacionalismos nos vários países africanos, não restava à sociedade crioula guineense outra opção que dar uma feição nacional aos projetos que elaborava para si, fracassada que estava a possibilidade de ser uma elite de segunda categoria, cujo devir não ia além da continuação de sua subalternidade perante um estrato governante metropolitano aliado a certas parcelas dos sempre imprevisíveis cabo-verdianos, que ali podiam exercer cotidianamente o mando de fato, a despeito das resistências locais e de alguns reclames pró-forma dos quase-sempre impotentes portugueses continentais.

Minha primeira hipótese é, então, que o projeto nacionalista que derrotou pela luta armada o colonialismo português na Guiné foi uma das formas encontradas pela sociedade crioula de vislumbrar para si um devir coletivo ${ }^{1}$. Porém, se a ideia crioula de uma nação guineense continha, como deve conter, algum germe de integração das diferenças existentes na vida colonial (entre os mais variados grupos étnicos, as muitas unidades políticas tradicionais, associadas ou não, exclusivamente ou não, aos grupos étnicos, as posições de classe que se consolidavam, os grupos de status, e as muitas outras unidades de natureza corporada), tal integração tomava a forma da típica incorporação antropofágica que estruturalmente caracteriza a reprodução das sociedades crioulas (TRAJANO FILHO, 2010, p. 157).

O problema é que uma contradição se consolidou no coração do projeto para a nação do PAIGC ou, o que dá no mesmo, da sociedade crioula desde o início do movimento nacionalista: um confronto paradoxal entre o retorno às origens idealizado na utopia de Cabral (1973), que sugeria um devir igualitário e horizontal para a futura nação, e a estrutura verticalizada da sociedade crioula, sempre supondo formas de incorporação da diferença que geravam hierarquias do tipo

\footnotetext{
${ }^{1}$ O conceito de nação e seus derivados (nacionalismo, estado nacional e outros) tem sido objeto de acalorados debate nas Ciências Sociais, dos quais passarei ao largo. Para os propósitos desse trabalho, importa apenas reafirmar minha percpectiva sobre o tema: a nação é uma comunidade de sentimento que se cristaliza em projetos de diferentes matizes e estilos em competição na arena política. Tais projetos podem ser institucionalmente formulados (pelo Estado, partidos polítos, instituições da sociedade civil, movimentos sociais) e tomar a forma de textos de estilos variados (programas, leis, panfletos, declarações, ensaios...), mas podem também ter uma autoria difusa e ganhar expressão pública nos rumores disseminados de modo apaixonado e dramatizado nas rodas de conversa, nas estórias exemplares e em outras formas narrativas tradicionais. Desnecessário é dizer que como antropólogo tenho um fascinio maior pela nação não official dos rumores, obviamente, sem perder de vista os projetos instituiconais. A esse respeito ver Trajano Filho $(1993,1998,2002$ e 2005).
} 
gerontocrático e patrimonialista. Historicamente, o mundo crioulo das cidades guineenses sempre fez uso de mecanismos de reprodução social que acentuavam as assimetrias e as diferenças entre os grupos envolvidos no compromisso do qual surgiu a sociedade crioula nas fortificações (as chamadas praças crioulas) da costa da Guiné, habitadas por lusoafricanos mais ou menos "cristianizados"2. Em outras palavras, a utopia igualitária do projeto crioulo para a nação de Cabral foi produzida num contexto sociológico e histórico de reprodução social extremamente conservador, tal como já foi classicamente descrito por Kopytoff(1987), carcterizado por hierarquias cristalizadas.

\section{Sociedade crioula e seu polimorfismo}

Para que o meu argumento faça sentido, esclareço o que entendo por sociedade crioula. Como definição de trabalho, considero que tal termo se refere ao aglomerado de pessoas que nasceram ou foram criadas nas praças construídas às margens dos rios da costa guineense desde a metade do século XVI. É composta, portanto, por gente de descendência mista, com laços orgânicos e íntimos com as sociedades africanas que circundavam essas povoações e com os mercadores e administradores portugueses e cabo-verdianos que comerciavam em África ou serviam nessas fortificações. Vale dizer que se trata de uma formação social original, uma entidade terceira, diferente das vertentes africanas e ibéricas que a constituíram, mas mantendo com elas alguma forma de continuidade cultural e compartilhando alguns mecanismos de reprodução de sua organização social. Historicamente, a sociedade crioula sempre teve uma pequena dimensão demográfica e sempre dependeu do bom desempenho do papel de intermediária no comércio intersocietário. No que toca a seu vínculo estratégico com os regimes de troca, noto que o mundo crioulo esteve ligado ao fluxo de coisas e gente entre as duas principais zonas ecológicas da África ocidental (a da floresta, que vai do sul da atual Guiné-Bissau até a Libéria, e a zona de savana e do Sahel, que começa no norte da Guiné-Bissau e chega à atual Mauritânia) assim como teve uma participação, direta ou indireta, no tráfico atlântico de escravos. A respeito de sua pequena dimensão demográfica, a sociedade crioula nunca teve, até a chegada do tempo do nacionalismo, massa crítica bastante para se reproduzir sem que tivesse

\footnotetext{
2 Essas formas hierárquicas caracterizam as culturas políticas de toda a região conhecida como alta costa da Guiné, não sendo, portanto exclusiva da sociedade crioula guineense. Sobre isto, ver Murphy (2010).
} 
que incorporar gente, valores e práticas sociais estrangeiras (indígenas ou europeias), transformando tudo isto em algo que era percebido como autenticamente crioulo.

Durante toda a sua existência, desde o final do século XVI, a sociedade crioula tem se caracterizado por uma grande heterogeneidade. Sincronicamente, nota-se uma variação interna que toma a forma de uma oposição complementar entre um centro dominante e uma periferia de recém-chegados, dependentes e aderentes por laços diversos ao núcleo central. Tendo como motivação o comércio intersocietário, a relação, sempre complexa e tensa, entre a minoria europeizada que compunha o seu núcleo e a periferia de recém-chegados, fortemente enraizada no universo indígena africano, demandava, para ter continuidade e ser produtiva, uma forma institucional de reciprocidade que fosse eficiente na regulação dos fluxos de mercadorias, gente e valores entre o universo crioulo e as sociedades indígenas ao seu redor. Tal padrão de relacionamento, conhecido na literatura como reciprocidade entre os "donos do chão" e os "estrangeiros", era um mecanismo já em uso, antes da chegada dos europeus, pelas sociedades daquela porção do continente africano para conceber, categorizar e lidar com a alteridade no contexto das trocas comerciais, de modo a acomodar os estrangeiros nas sociedades hospedeiras, quando estes a elas vinham com o fito de estabelecer trocas comerciais regulares ${ }^{3}$. Ocasionalmente, a variabilidade sincrônica também se manifesta nas aparentes oposições (também complementares) entre a elite crioula urbana e os grupos subalternos de origem rural, entre os cristãos e os adeptos crioulos das religiões e cultos locais, e no contínuo colonial entre civilizados, assimilados e indígenas ${ }^{4}$.

Diacronicamente, a variabilidade da sociedade crioula é de interesse direto a esse trabalho e por isto eu a trato com mais vagar, destacando três períodos históricos, cada um com sua forma dominante. O primeiro momento coincide com o início do processo de crioulização nas praças fortificadas dos rios da Guiné no final do século XVI e vai até o fim do comércio atlântico de escravos em meados do século XIX. Neste período, a sociedade crioula tinha como elemento constituidor as $G \tilde{a} s$ - casas

\footnotetext{
O estudo pioneiro sobre este tipo de relacionamento, conhecido na literatura anglófona como landlord-stranger, se encontra em Dorjahn e Fyfe (1962). Importantes também são as já clássicas contribuições de Rodney (1970), Curtin (1975) e Brooks $(1980,1993)$ sobre o funcionamento deste tipo cultural de reciprocidade na Senegâmbia e costa da Guiné. Ver também os trabalhos recentes de Sarró (2010), Højbjerg (2010) e Murphy (2010) sobre esse padrão de reciprocidade.

4 Sobre essas classificações coloniais, ver Trajano Filho (1998: 81-101). Barbosa (1947), Tavares (1947), Duffy (1959), Brito (1966) e Cardoso (1992) também tratam extensivamente dessas categorias.
} 
patrimoniais encabeçadas por comerciantes portugueses e luso-africanos que incorporavam como aderentes, dependentes e clientes os indígenas recém-chegados às praças crioulas (chamados até o início do século $\mathrm{XX}$ de grumetes) e membros das famílias de notáveis das sociedades indígenas. Relativamente autônoma e completamente envolvida nas relações de troca que tinham no tráfico atlântico de escravos o seu eixo central, a $G \tilde{a}$ crioula era constituída por meio de laços de sangue, casamento e residência e um kit completo de relações clientelísticas. Como um grupo corporado de parentesco bilateral, ela articulava o comércio inter-societário, mediando as relações e os interesses dos chefes e régulos africanos, dos traficantes euro-americanos e do pequeno grupo de funcionários e militares portugueses que exerciam nominalmente o governo das praças. Casamentos poligínicos e exogâmicos com mulheres oriundas do mundo indígena, em geral as filhas e irmãs dos chefes locais, e a observância de tabus rituais e valores místicos das sociedades tradicionais eram cruciais para a articulação de seu núcleo central com as sociedades indígenas com quem comerciava ${ }^{5}$. Gravitavam em torno dos cabeças das $G a ̃ s$ vários núcleos secundários, organizados basicamente pelos mesmos princípios que presidiam o funcionamento do núcleo central, dando origem a um complexo conjunto de relações de dependência, patronagem e clientelismo. Por meio dessas relações,

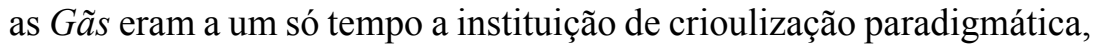
as unidades econômicas mais fundamentais e a verdadeira fonte da autoridade das praças crioulas. Era, sobretudo, como membros desses grupos corporados que os moradores das povoações crioulas interagiam entre si e com as sociedades tradicionais que os circundavam, orientados pelo padrão de reciprocidade "dono do chão-estrangeiro".

O declínio do tráfico atlântico e a implantação, por volta de 1840 , das plantações de amendoim marcam o início do segundo momento histórico, no qual a sociedade crioula assume a forma de um grupo de elite. A partir deste momento, a unidade básica da sociedade crioula deixou de ser os grupos corporados de parentesco bilaterais e passou a ser a praça crioula diversificada, mas englobada por uma elite que se distinguia da massa de grumetes por meio de uma mística da exclusividade. Os principais traços criadores de sua exclusividade eram uma etiqueta linguística que valorizava o uso da língua portuguesa, os

\footnotetext{
${ }^{5}$ Igulamente estratégicos, exogâmicos e complementares eram os "casamentos" das mulheres da elite crioula com funcionários portugueses e cabo-verdianos de estratos mais elevados. Curiosamente, a elite crioula tendia a ver essas alianças matrimoniais como uma forma de se casar dentro do grupo.
} 
valores cristãos como a caridade, o uso e a posse de dinheiro e um estilo de vida ou formas de sociabilidade que, supostamente, a ligava a um Portugal imaginário. Porém, nem a metrópole portuguesa impotente e distante nem a ideia abstrata de uma comunidade cristã podiam ancorar por muito tempo um projeto de identidade crioula para essa elite, pois eram instituições muito distantes da vida cotidiana nas praças guineenses. A vida social continuava a gravitar em torno do comércio, os meios de produção e as forças produtivas ainda permaneciam nas mãos dos chefes indígenas locais, que tinham completo controle dos territórios que governavam. De modo bastante curioso, enquanto as Gãs crioulas lutavam para se tornar uma elite cristianizada e civilizada, buscando acesso às poucas posições abertas na administração colonial, continuando, porém, a atuar como intermediários nas trocas com os indígenas, um conjunto de oficiais portugueses e de mercadores europeus (alemães, franceses e italianos) recém-chegados procuravam se introduzir nas redes de relações sociais organizadas pelo padrão de reciprocidade "dono do chão-estrangeiro" e se tornar cabeças de incipientes Gãs.

Neste contexto de crescente presença europeia nas praças guineenses, a elite crioula, pequena e isolada, precisava de uma moldura encompassadora para basear seu projeto identitário. As duas primeiras décadas do século XX representaram um período histórico de transição e de mudança. A autoridade portuguesa foi plenamente estabelecida na Guiné após dois triunfos estratégicos: as vitórias militares contra as sociedades indígenas que resistiam à ocupação de seus territórios e se recusavam a pagar o imposto de palhota e a vitória política sobre os luso-africanos educados da Liga Guineense, que aspiravam mobilizar os seus dependentes - os grumetes da periferia crioula - em apoio à causa do desenvolvimento e da relativa autonomia administrativa da Guiné Portuguesa, de modo a que manter o prestígio que eles até então desfrutavam. Naquele momento, o projeto aparentemente hegemônico que ela elaborou para si mesma enfatizava duas dimensões da ideia de unidade na diversidade. A primeira dimensão a representava como uma totalidade heterogênea ancorada em um espaço mais amplo do que as praças, um espaço coincidente com o território da colônia que gradualmente se tornava integrado. A imagem espacial dessa totalidade englobava todos os aglomerados crioulos bem como os espaços não urbanos das pontas ${ }^{6}$ e dos entrepostos comerciais do interior. Neste

\footnotetext{
${ }^{6}$ Palavra crioula, de origem portuguesa, que dá nome às propriedades rurais da elite luso-africana
} em que se plantavam o amendoim, a cana de açúcar e se destilava a aguardente. 
momento em que a sociedade crioula já não mais se percebia como uma elite homogênea que representava localmente os valores e interesses portugueses, a categoria híbrida de identificação "Guiné Portuguesa" começou a ganhar ascendência sobre outras. Passou a predominar a ideia de uma pluralidade formada por grupos diferenciados, mas ligados uns aos outros por uma identidade comum, por uma língua, formas de sociabilidade e uma história próprias, mas por interesses muitas vezes conflitantes. Mas, numa segunda dimensão, tratava-se de uma totalidade subordinada lógica, social e politicamente - uma Guiné que era englobada pela categoria Portugal, que a partir do fim do regime monárquico em 1910 se fez ali presente como nunca dantes havia feito $^{7}$. E mesmo assim este foi um projeto derrotado. A ideologia colonial e a cultura política então em vigor na metrópole republicana não ofereceram, por algum tempo, espaço para a afirmação de uma diferença legítima. A sede civilizadora e cristianizadora portuguesa pretendia a tudo incorporar e mudar, a tudo tornar português. Porém, a debilidade da potência colonial não conseguiu mais do que fazer hibernar os projetos de autonomia, que renasceram revigorados nos anos 50 .

A partir de meados da década de 1950 iniciou-se o momento histórico caracterizado pela hegemonia dos projetos identitários que representavam a sociedade crioula pela via da nação. São vários projetos em competição que têm em comum pouco mais do que um entendimento da sociedade crioula como uma unidade incorporadora de diferenças regionais, étnicas, históricas, linguísticas e sociais ${ }^{8}$. Aglutinados em dois extremos, a competição entre eles toma, por um lado, a forma de um projeto nacional de natureza universalista, racional e jurídica, cujos principais sujeitos formuladores foram o PAIGC e, mais tarde, o Estado que durante muito tempo o partido controlou. Trata-se de um projeto institucional que, em nome de um suposto universalismo, propõe uma nação claramente subordinada ao Estado e esvaziada de contradições e de sentido. Por outro, existe o difuso projeto formulado nos discursos

\footnotetext{
7 Isto explica, em parte, a falta de uma ação coordenada comum por parte da elite crioula. De ínicio, ela colaborou com os militares metropolitanos na construção de uma Guiné Portuguesa, contra os indígenas rebeldes. Depois, ela se dividiu, um grupo continuou colaborando, mas numa posição claramente subalterna; a outra parte foi derrotada em seu pleito por autonomia e equiparada aos grumetes (os membros da periferia crioula, quase indígenas, no sentido analítico).

8 Curiosamente os projetos mais "africanos" buscavam excluir os cabo-verdianos, vistos como os agentes da violência dominadora, da futura nação guineense e adotavam, de modo geral, uma postura de menor confrontação com o governo colonial, admitindo a hipótese de autonomia e uma eventual independência negociada. O projeto do PAIGC, visto por alguns membros da elite crioula como perpetuador da subrodinação dos guineenses ao cabo-verdianos, era mais radical e desde o início propugnava a independência total da Guiné e de Cabo Verde.
} 
cotidianos e nos rumores que circulam pelas cidades que criam, através de uma algazarra de vozes e com símbolos próprios do ecúmeno cultural africano, a comunidade imaginada que é a nação. Diferentemente da nação do Estado, a nação dos rumores é uma totalidade aberta, dinâmica e contraditória, baseada em formas locais de institucionalização da autoridade e de concepção da pessoa como membro da nação.

No restante desse trabalho quero examinar os contornos do projeto institucional formulado pelo PAIGC e algumas de suas tensões internas. Para tal, esboçarei de modo esquemático uma breve história factual dos principais momentos de instabilidade politica e institucional passados pelo país desde a independência, bem como mencionarei brevemente os problemas relacionados aos projetos de desenvolvimento econômico dos últimos 42 anos $^{9}$. Desnecessário é dizer que as raízes e as causas de muitos dos conflitos e tensões vividos no período examinado já estavam presentes durante a fase da guerra de libertação e, antes dela, nas disputas e polêmicas que estavam em ebulição no momento em que os vários grupos nacionalistas começaram a se organizar na Guiné da segunda metade da década de 1950. Por razões de espaço, deixarei de lado o exame deste período, mas noto que há uma vasta literatura, de qualidade e inspiração teórica e ideológica variadas, sobre o assunto ${ }^{10}$.

\section{Instabilidades políticas depois da Independência: linhas de clivagem}

A independência política da Guiné foi um ato unilateral, proclamado pelo PAIGC em 24 de setembro de 1973 em Madina do Boé, no coração das áreas libertadas pelos combatentes nacionalistas. Demorou quase um ano para que Portugal, renovado pela Revolução de abril, reconhecesse a independência do país em 10 de setembro de 1974. Os primeiros

\footnotetext{
9 Nunca é demais enfatizar a forma esquemática da revisão dos acontecimentos politicos que se segue e a forma arbitrária que presidiu a escolha de certos eventos em detrimento de outros. A razão da existência das duas próximas seções do texto não é contar resumidamente a história política e econômica da Guiné depois da independência, o que já foi feito com maior ou menor grau de sucesso por muitos analistas guineenses e europeus, mas, antes, subsidiar o argumento final de que apesar das dificuldades imensas enfrentadas pela sociedade guineense na construção de instituições estatais em moldes europeus e dos entraves colocados a isto pela cultura política e pela economia moral das sociedades indígenas locais (inclusive da sociedade crioula), o processo de construção nacional tem avançado. Por trás, portanto, do pessimismo entranhado das duas próximas seções, a intenção não é repetir mais uma vez a tese do estado falhado, mas de afirmar a da nação que se reinventa diariamente num esforço de dubriagem fascinante.

${ }^{10}$ Ver, entre muitos outros, Rudebeck (1974), Chabal (1983), Galli and Jones (1987), Lopes (1987), Silva (1997), Dhada (1993), Forrest (2003), Nóbrega (2003), Pereira (2003), Sousa (2011), Amado (2013), Djaló (2013).
} 
anos de vida independente foram um tempo de grande otimismo e efervescência para os guineenses de maneira geral e para a sociedade crioula do meio urbano. O projeto nacional igualitário formulado por Amílcar Cabral também atraiu para o novo país uma grande quantidade de profissionais europeus, no ingênuo anseio de participação numa experiência "socialista africana", e uma substancial ajuda internacional (majoritariamente vinda da Europa do Leste e da Escandinávia) sob a forma de projetos que visavam o desenvolvimento nacional. Apesar de tudo isto, o partido que levou a Guiné à independência e o próprio Estado, que com o partido se confundia, entrou em Bissau vivendo uma dramática crise.

Poucos meses antes da declaração de independência, a 20 de janeiro de 1973, Cabral é assassinado em Conakry por Inocêncio Cani (Kany), um comandante naval que já fora membro do Conselho Executivo da Luta do partido, mas que, na altura do ocorrido, estava posto de lado em razão de más práticas políticas associadas ao desvio de bens do partido em proveito próprio. $\mathrm{O}$ assassinato do Secretário Geral e líder histórico do PAIGC foi o ponto culminante trágico de uma intricada trama que envolvia um grande número de dirigentes partidários insatisfeitos com o comando e liderança de Cabral e com o peso da presença caboverdiana nos órgãos máximos do partido ${ }^{11}$. O desfecho do complô foi mal resolvido, as apurações sobre as responsabilidades individuais foram abafadas ou impedidas de serem tornadas públicas e as punições dos prováveis culpados envoltas em grande mistério. Acusações de envolvimento direto e indireto com o assassinato tornaram-se comuns nos diversos lances de acerto de contas entre as muitas linhas de clivagem no interior do partido e entre as lideranças rivais. Além disto, tais acusações tornaram-se moedas de uso corrente nas disputas internas que tiveram lugar para a sucessão de Cabral e para a formação do futuro governo da Guiné. O Congresso de Boé, o segundo do partido, realizado entre 18 e 22 de julho de 1973, foi o palco institucional das lutas que conduziram a um reequilíbrio frágil entre as várias correntes internas.

\footnotetext{
${ }^{11} \mathrm{O}$ assassinato de Cabral permanece envolto em escuras brumas e tem sido tema de acaloradas polêmicas entre historiadores e analistas da vida política guineense e cabo-verdiana. Parece não haver dúvidas de que Cani foi o executor de Cabral, mas todo o resto, em especial, o cabeça de toda a operação é tópico para disputas. Há autores que apontam para a PIDE ou para o comando militar português na Guiné, na altura chefiado por Spínola, outros sugerem que o Presidente da Guiné-Conakry, Sekou Tourê, tenha sido o cabeça do complô, outros ainda remetem toda a trama aos conflitos internos de longa data entre os nacionalistas guineenses. Ver entre outros Ignatiev (1975), Chabal (1983), Dhada (1993), Castanheira (1995), Sousa (2011) e Lopes (2012). Se na literatura acadêmica grassa a polêmica, nos rumores e nas estórias contadas nas ruas de Bissau e da Praia praticamente cada pessoa tem sua própria e idiossincrática versão do ocorrido.
} 
Nele, a presença dos quadros guineenses (sobretudo os de origem rural) no Conselho Superior da Luta foi aumentada. Lideranças suspeitas de envolvimento no assassinato foram afastadas de modo obscuro e foi criado um Secretariado Permanente que representava um compromisso entre guineenses e cabo-verdianos (LOPES, 1987, p. 92-93). Foi no Congresso de Boé que se deu início à preparação da independência, que culminou com a eleição da Assembleia Nacional Popular (ANP) e a designação dos titulares do Conselho de Estado e do Conselho dos Comissários de Estado.

Instalado e reconhecido o primeiro governo, presidido por Luís Cabral, irmão de Amílcar e co-fundador do PAIGC, inicia-se o custoso processo de formação do Estado e de reconstrução institucional. Esse foi um tempo de efervescência que parece ter abafado as tensões e disputas no seio do partido. Teve, porém uma duração breve. Em 1977 conhecemos a primeira tentativa explícita de golpe, encabeçada por uma antiga liderança partidária associada a ex-comandos (militares africanos que combateram ao lado dos portugueses) que então residiam no Senegal. O cabeça do golpe, Malam Sanhá, era um militante de longa data. Aparentemente, ele era influente entre oficiais e soldados das forças armadas bem como entre militantes dissidentes do PAIGC ${ }^{12}$. Essa tentativa foi frustrada, o líder, preso e suicidado na prisão e seus homens fuzilados posteriormente.

Francisco Mendes, conhecido como Chico Té, Comissário Principal do Estado guineense (uma espécie de primeiro-ministro) morreu em julho de 1978, num acidente de carro misterioso, quando o Presidente do Conselho de Estado, Luís Cabral, se encontrava no exterior. A confiar nos rumores que ainda circulam no país, não se tratou propriamente de um acidente, mas de uma eliminação política. Chico Té parecia estar descontente com as tendências centralizadoras do Presidente Cabral, que retirava as principais atribuições do cargo que ele ocupava. Parece também que havia uma rivalidade latente entre Chico Té e Nino Vieira, que então era o terceiro na hierarquia do Partido-Estado ${ }^{13}$.

O regime liderado por Luis Cabral foi derrubado em 14 de novembro de 1980 por um golpe comandado por Nino Vieira, então o número

\footnotetext{
${ }^{12}$ Entre lideranças dissidentes ou insatisfeitas que estariam ligados de alguma forma a Malam Sanhá, destaca-se o nome de Nino Vieira, na altura o terceiro homem na hierarquia do Estado. Ver Nóbrega (2003, p. 217-218). Lopes (1987, p.280) afirma que essa tentativa de golpe ocorreu em novembro de 1978 e foi liderada não só por Sanhá, mas também pelo primeiro presidente do PAIGC, o histórico Rafael Barbosa, eterno candidato a traidor.

${ }^{13}$ Entre outros, Aristides Pereira, então Presidente da República de Cabo Verde e Secretário-Geral do PAIGC, levanta suspeita sobre a morte de Chico Té. Ver Lopes (2012, p. 268).
} 
dois na hierarquia do Partido-Estado. Isto ocorreu na esteira de uma série fracassos econômicos, insatisfação camponesa com as políticas do Partido-Estado para o mundo rural, repressão violenta contra chefes tradicionais e dissidentes do regime, intensas rivalidades no seio do corpo dirigente do PAIGC e uma desconfiança generalizada em relação aos cabo-verdianos que, se segundo se acreditava, ocupavam muitos cargos no topo da estrutura partidária, dominavam a burocracia institucional do Estado guineense e, no Estado-irmão de Cabo Verde, se distanciavam da utopia de Cabral acerca da unidade com a Guiné. O presidente foi inicialmente colocado sob prisão e depois forçado a deixar a Guiné. Morreram dois dirigentes no dia do golpe e um terceiro se "suicidou" na prisão, uma repressão difusa se fez sentir inicialmente contra os então chamados burmejus (literalmente, "vermelhos", um eufemismo para designar os cabo-verdianos) do PAIGC e das instituições estatais. Depois de alguns realinhamentos das forças políticas, o Partido-Estado se manteve no poder, a elite dirigente permaneceu intocada (GALLI; JONES, 1987, p. 100-101) e as linhas gerais da governação pouco mudaram, além da retórica de mais apoio à agricultura e às demandas do mundo rural e da interrupção dos projetos de desenvolvimento voltados para a industrialização do país (montadora de carros Citroen, oficina de manutenção da Volvo, fábrica de oxigênio e acetileno, usinas de processamento de amendoim, fábricas de cerveja, colchões, refrigerantes, compotas etc.). Vale dizer que tais interrupções não se deveram a razões político-ideológicas, mas, antes, à má planificação, às imensas despesas de manutenção, à falta de capital para continuar investindo e à carência de recursos humanos locais para gerenciar e operar tais projetos. Em outras palavras, eram projetos já há muito falidos quando se deu o golpe.

O maior desdobramento do 14 de novembro foi o fim sonho utópico de um mesmo partido governar dois Estados nacionais ao ponto de, no futuro, os dois se unirem numa única entidade supranacional. Em Cabo Verde, as reações ao golpe e aos contornos xenofóbicos que inicialmente emergiram associados à deposição de Luís Cabral foram agudas. Nas ilhas, logo se percebeu que Guiné e Cabo Verde eram unidades políticas muito diferentes em quase todos os aspectos que se considerassem ${ }^{14}$. Afora uns poucos inusitados movimentos de cabo-verdianos em apoio a Nino Vieira, a tendência geral foi de afastamento e ruptura institucional,

\footnotetext{
${ }^{14}$ Trajano Filho (2014) analisa as imagens da África e da Guiné elaboradas pelos cabo-verdianos e argumenta que, em vez de semelhanças, aproximações ou mesmo identidade, o guineense é o outro paradigmático dos ilhéus.
} 
que não demorou muito a acontecer. Assim, em 20 de janeiro de 1981, aniversário do assassinato de Amílcar Cabral, o Conselho Nacional de Cabo Verde do PAIGC decidiu criar o Partido Africano da Independência de Cabo Verde (PAICV), que passou a governar o Estado insular de modo autônomo dois meses depois do golpe em Bissau. Analisando com a devida distância, parece que por trás da forte retórica empregada pelos cabo-verdianos, a qualificar o golpe como uma traição ao pensamento do herói da libertação das duas nações, e do corte das relações diplomáticas, o acontecido na Guiné serviu como uma boa desculpa para os dirigentes dos dois países se livrarem do fardo de uma unidade impossível (SILVA, 2010, p. 193).

Carlos Lopes (1987, p. 281) menciona a ocorrência em março de 1982 de uma tentativa de desestabilização do regime originada no interior do próprio partido dirigente. De fato, distúrbios graves ocorreram na sede da Brigada Mecanizada associados a rumores sobre uma tentativa de golpe de Estado. Disto resultou a morte de um capitão, um inquérito que nada concluiu, e mas aqueceu o forno das intrigas do Comandante Iafai Camará (membro do Conselho da Revolução e o terceiro na hierarquia do poder), em aliança com o Ministro do Interior, Manuel Saturnino da Costa, contra o Ministro das Forças Armadas, Paulo Correia e o Procurador-Geral da República, Viriato Pã ${ }^{15}$. Este evento foi o prenúncio dos acontecimentos de outubro de 1985, que levaram à prisão e, mais tarde, ao fuzilamento desses dois dirigentes de outros quatro comandantes militares, todos da etnia balanta.

Antes, porém, dessa polêmica tentativa de golpe, no país que continuava a viver as mesmas desgraças de antes do 14 de novembro de 1980, com uma estagnação econômica aguda e recorrentes crises de abastecimento, insatisfações nas casernas, enriquecimento ilícito de alguns chefes militares e o ressurgimento do aparato repressor, as rivalidades no seio do Conselho da Revolução e do Conselho de Ministros provocaram a queda do Primeiro-Ministro Victor Saúde Maria. Mas não se tratou de uma mera mudança no gabinete governativo para atender a um realinhamento das alianças políticas. Nino Vieira acusou o primeiro-ministro, um dos primeiros a apoiar o movimento de 1980, de preparar um golpe e o expulsou do PAIGC, assim como uma série de outros militantes partidários de alto escalão, todos eles tendo em comum o fato de serem quadros políticos (e técnicos), não tendo um passado de comandantes militares (NÓBREGA, 2003, p. 236-239).

\footnotetext{
${ }_{15}$ Ver também Nóbrega (2003: 233-235) e Galli e Jones (1987: 104).
} 
O golpe de 1980 pouco alterou a vida na Guiné-Bissau. A economia continuou patinando com inflação elevada, défices crescentes no orçamento do Estado, crises regulares de abastecimento, diminuição da ajuda internacional, aumento do contrabando e da economia paralela à institucional. $\mathrm{O}$ estado da infraestrutura do país permaneceu inalterado em sua decrepitude, a educação e a saúde em crise, o funcionalismo público sem receber os salários e as perspectivas para o futuro, pouco animadoras. Na política, contudo, houve mudança. O poder passou a ser mais concentrado nas mãos do presidente e os militares, especialmente os antigos combatentes, se tornaram um fator determinante na manutenção e uso do poder, tornando-se desde então numa fonte de instabilidade política, quando as reivindicações do estamento não eram atendidas.

Neste contexto, levando em conta a elevada participação de combatentes balantas nas Forças Armadas do Povo (FARP) e a crença generalizada de que tal participação fora essencial para o êxito militar do PAIGC, Nino Vieira parece ter visto a presença de dois quadros balantas em elevadas posições na hierarquia do governo como uma ameaça ao seu projeto de poder a continuidade. Paulo Correia era vice-presidente do Conselho de Estado e o segundo homem na hierarquia do país. Era um homem público popular, um comandante respeitado nas FARP por sua participação destacada na luta de libertação e no golpe de 1980 e tinha, segundo o Presidente de Cabo Verde, Aristides Pereira, uma certa ascendência sobre os balantas, especialmente sobre os militares dessa etnia. Além disto, ele se destacava no mundo das casernas, cujos membros eram, de modo geral, gente pouco instruída, por ter investido em sua educação, tornando-se de fato um homem de Estado. Em outubro de 1985, doze anos após a independência, ele já tinha sido ministro de várias pastas, entre outras, a da Justiça e Autoridades Locais e a das Forças Armadas, do Desenvolvimento Rural, bem como tinha sido membro do Conselho de Estado, escolhido pela ANP em 1973. Isto teria incomodado o Presidente Nino Vieira, que não fizera tal investimento e, por isto, estava alguns palmos abaixo do comandante balanta (NÓBREGA, 2003, p. 243; LOPES, 2012, p. 290-291).

Viriato Pã também era um homem de prestígio na Guiné de então. Um dos poucos guineenses que havia obtido uma licenciatura em Direito numa universidade portuguesa, Viriato vivia como advogado em Lisboa até ter sido convocado por Nino Vieira para retornar à Guiné depois do golpe de 1980. Mal chegado a Bissau, assumiu a ProcuradoriaGeral da República e ali ficou até ser destituído, passando a exercer a advocacia. 
Segundo Nóbrega (2003, p. 243-244), essa dupla de homens balantas representava, aos olhos de Nino Vieira, uma ameaça à sua perpetuação no poder. Assim, em meio a um turbilhão de intrigas que tão bem caracteriza o cotidiano político em Bissau, pessoas próximas ao presidente como o chefe da Casa Civil, João Monteiro, da etnia papel como Nino, o convenceram do andamento de um golpe liderado por Paulo Correia, apoiado pelos balantas das FARP. Os serviços de segurança agiram rápida e violentamente. Foram detidas quase uma centena de pessoas, incluindo membros históricos do PAIGC, bem como militares balantas de alta patente. A tortura campeou e, mesmo antes do julgamento farsesco começar, alguns dos detidos tiveram a má ideia de morrer na prisão, sempre de causas naturais. Apesar da pressão internacional demandando clemência para os condenados num julgamento polêmico, o regime fuzilou e enterrou os "culpados" balantas.

O Presidente Aristides Pereira, em entrevista a João Vicente Lopes, afirmou que com a morte de Paulo Correia, Nino assinou a sua sentença de morte, ocorrida cerca de 24 anos depois em 3 de março de 2009 (LOPES, 2012, p. 290). Ele foi vítima da ação de comandos balantas vindos de Mansoa para vingar o atentado que havia vitimado o Chefe das Forças Armadas, o general Tagme Na Waie, no dia anterior, aparentemente a mando de $\mathrm{Nino}^{16}$. Os rumores a que tive acesso afirmam que um dos líderes desse comando que justiçou o presidente foi um major médico balanta que tinha um braço amputado por causa das torturas a que fora submetido a mando de Nino em 1985, quando da suposta tentativa de golpe liderada por Paulo Correia (TRAJANO FILHO, 2008). Vale lembrar que o general assassinado era um sobrevivente das purgas feitas em 1985 no bojo dos acontecimentos envolvendo Paulo Correia.

Protegido pelos órgãos de segurança que exercia uma estreita vigilância sobre a vida privada dos guineenses, Nino sobreviveu ao processo de liberalização que deu fim tanto à centralização da economia quanto à moeda nacional (o peso guineense), e à implantação de um regime político multipartidário. Foi o candidato que venceu no segundo turno as primeiras eleições multipartidárias em 1994, mantendo o

\footnotetext{
${ }^{16}$ Os detalhes dessa trama provavelmente nunca virão à tona, mas, a confiar na "verdade" dos rumores, que não se confunde com a verdade histórica, atestada e controlada por instituições do Estado e por profissionais por elas reconhecidos para tal efeito (historiadores, sociólogos, cientistas políticos, jornalistas etc.), estando mais próxima das condições de felicidade, tais como propostas por Austin (1962), é bastante gramatical a versão que coloca Nino Vieira como um ator central na morte do seu Chefe das Forças Armadas.
} 
PAIGC no poder. Não completou o mandato, tendo sido deposto em 1999 pelo Chefe do Estado-Maior das Forças Armadas, Ansumane Mané, no desfecho de uma guerra civil que durou meses e que implicou o envolvimento de tropas senegalesas e da Guiné-Conakry. Seguiu-se a sua deposição e, depois de dois presidentes interinos, a eleição do balanta Kumba Yalá, pelo Partido da Renovação Social (PRS) e uma clara balantização do poder, sobretudo, nas FARP. Nos três anos que permaneceu no poder, Kumba Yalá tentou promover um grande número de oficiais militares balantas, no que teve a oposição do então prestigiado general Ansumane Mané, que havia sido vitorioso contra Nino. Mané tentou revogar as promoções do presidente e substituir o Chefe do Estado-Maior, Veríssimo Correia Seabra. Seguiram-se alguns dias de luta que resultaram em sua morte em abril de 2004. A instabilidade política prosseguiu, tendo o Presidente Yalá, dissolvido a ANP e aprisionado membros da oposição. Nesse período, a economia continuou estagnada e a ajuda financeira das agências multilaterais (a principal fonte de financiamento do Estado) foi cortada.

Nesse contexto de instabilidade política e debilidade econômica, o que se sucedeu foi mais uma vez o esperado. O Chefe das Forças Armadas, Veríssimo Correia Seabra, filho de pai cabo-verdiano e de mãe manjaca, depôs o Presidente Yalá, e assumiu a presidência interinamente. Depois de um amplo acordo político, ele foi sucedido, também de modo interino, por um membro da elite crioula, o empresário Henrique Rosa, que preparou as eleições gerais. Estas foram vencidas de modo apertado por Nino Vieira, que retornara teatralmente do exílio em Portugal. A terceira vez em que assumiu o poder na Guiné não foi diferente das outras. Nino tentou concentrar o poder em suas mãos, entrando em conflito aberto com o Primeiro-Ministro Carlos Gomes Júnior, a quem demitiu. Porém, diferentemente das vezes anteriores, Nino era de certo modo tutelado pelos militares, no caso, pelo general Tagme Na Waie e pelo almirante Bubo Na Tchuto (ambos de origem balanta) ${ }^{17}$. Quando tentou escapar da tutela, supostamente plantando a bomba que vitimou o general $\mathrm{Na}$ Waie, foi violentamente assassinado por um comando balanta, fechando tragicamente a reciprocidade negativa ou as trocas

\footnotetext{
${ }^{17}$ Essas personagens, juntamente com um grande número de oficiais das Forças Armadas e alguns empresários guineenses, estão envolvidas com a entrada da Guiné na rede do narcotráfico sulamericano. O almirante Bubo Na Tchuto foi detido pelo FBI em 2013 a bordo de um iate no meio do Atlântico e se encontra atualmente numa prisão norte-americana, acusado de chefiar o narcotráfico na costa ocidental africana. Segundo rumores correntes na Guiné, ambos foram os mandantes do assassinato do general Veríssimo Correia Seabra em 2004.
} 
de atos de violência iniciadas décadas antes, com os acontecimentos de outubro de 1985.

Nino Vieira foi sucedido pelo militante histórico do PAIGC, Malam Bacai Sanhá, que já havia exercido a presidência interina do país entre 1999 e 2000, com um longo currículo no exercício de cargos políticos. Os dois anos e meio em que exerceu a presidência (Setembro de 2009 a Janeiro de 2012) foram um dos períodos mais tranquilos na vida política da Guiné-Bissau pós-independência, o que não quer dizer que tenha sido sem tensões e conflitos ${ }^{18}$. A tutela dos militares ligados ao narcotráfico continuou a se fazer sentir e a pressão do estamento militar permaneceu inalterada. Tudo leva a crer que o crescente poder do Primeiro-Ministro Carlos Gomes Júnior, também presidente do PAIGC desde 2002, tenha sido de algum modo responsável por esse breve período de aparente estabilidade ${ }^{19}$.

O Presidente Sanhá faleceu inesperadamente em 2012 em razão de uma doença. O país ficou sob a presidência interina de Raimundo Pereira, que convocou eleições gerais. O Primeiro-Ministro Carlos Gomes Júnior se candidatou à presidência e por pouco não venceu no primeiro turno. Antes, porém, de haver o segundo turno, um golpe foi tramado pelos militares narcotraficantes (Antonio Ndjai e Bubo $\mathrm{Na}$ Tchuto), com apoio de grande parte do mundo político. Manuel Serifo Nhamadjo assumiu a presidência interina entre maio de 2012 e junho de 2014, num período em que Portugal, Brasil e um conjunto variado de países deixaram de reconhecer o governo guineense.

Depois de dois anos de relativo isolamento da comunidade internacional dos estados-nações e com a prisão pelo FBI de um dos líderes do golpe, por seu envolvimento com o narcotráfico, novas eleições foram realizadas, sendo eleito como Presidente o economista nascido na região de Cacheu José Mário Vaz. Para Primeiro-Ministro foi escolhido o engenheiro Domingos Simões Pereira, presidente do PAIGC, nascido em Farim. A coabitação entre os jovens governantes foi motivo de grande esperança entre os guineenses de um devir com estabilidade e desenvolvimento. O general Antonio Ndjai

\footnotetext{
${ }^{18}$ Conforme sugeriu um parecerista, a coabitação do Presidente Sanhá com o Primeiro-Ministro Carlos Gomes Jr. sempre foi um foco de tensão política.

${ }^{19}$ No entanto, vale lembrar que, em 2010, o almirante Bubo Na Tchuto, então asilado no quartelgeneral da $\mathrm{ONU}$, foi resgatado por um grupo de militares enquanto um outro grupo deteve o comandante das Forças Armadas e outros oficiais num quartel do exército, e um terceiro invadiu a residência do Primeiro-Ministro, numa tentativa de golpe liderada pelo almirante balanta e pelo general Antonio Ndjai (este também acusado de envolvimento com o narcotráfico e objeto de um mandado de captura internacional).
} 
foi demitido e, aparentemente, os militares deixaram de tutelar o governo civil.

Mas na Guiné, quase nada tem vida longa; o país parece não apreciar a previsibilidade. Pouco mais de um ano de coabitação e a tensão entre o presidente e o primeiro-ministro levou à substituição do segundo por Baciro Dja, por indicação do Presidente Vaz. O Superior Tribunal de Justiça impugnou tal nomeação, por ser ela atribuição do PAIGC, o partido vencedor das eleições. Depois de meses de tensões e acefalia no governo, o presidente nomeou novamente Baciro Dja para o cargo de Primeiro-Ministro em maio de 2016 numa composição política bastante instável.

\section{Os fracassos na economia moral}

A utopia da nação independente desenhada por Cabral não se cumpriu, apesar do otimismo inicial dos guineenses e dos cooperantes. A intenção do líder do PAIGC de governar para os camponeses, de reproduzir uma estrutura social horizontal, semelhante a dos balantas, e descentralizar o poder, implementando inclusive a ideia de uma capital itinerante nunca se cumpriu. Os vitoriosos, sem o carisma do líder assassinado, chegaram atropeladamente a Bissau, sem terem tido tempo de preparar a transição política nem de formar quadros para gerenciar a rotina da administração pública.

Luís Cabral foi levado, por causa de vicissitudes variadas, a implementar projetos de industrialização que teriam favorecido, se tivessem tido algum êxito, os estratos médios da população urbana, e a centralizar demasiadamente a economia em mãos do Estado. Os projetos industriais foram fracassos retumbantes e a centralização da economia beneficiou somente os dirigentes que ocupavam posições estratégicas nas empresas estatais. A crer nos saborosos rumores guineenses, todos eles enriqueceram muito e rapidamente, passando a ser os cabeças de redes patrimonialistas que sugavam o que mais podiam do Estado e da ajuda internacional que era farta nesses anos de algum otimismo. Como nódulos de frouxas redes de reciprocidade, esses funcionários-empresários construíram uma rede de clientes, aderentes e dependentes cuja natureza estrutural era muito semelhante ao sistema das Gãs do século XIX, mas sem as sanções de ordem cosmológica, orientadas pela reciprocidade "donos do chão" e "estrangeiros" que caracterizava as últimas.

Pouco tempo depois da vitória militar sobre os portugueses, a Guiné-Bissau via-se defronte de imensos défices orçamentais e 
crises recorrentes de abastecimento. Os bens de consumo importados chegavam com dificuldade aos "Armazéns do Povo", cujas prateleiras estavam sempre vazias. A produção local mal alcançava o mercado formal centralizado nas mãos das empresas do Estado. Uma política de preços desastrada fazia com que os camponeses produtores dos bens primários usassem suas redes de parentesco para fazê-los sair contrabandeados para os países vizinhos, onde eram comercializados a preços mais compensadores. Quando isto não se mostrava viável, eles apagavam a natureza mercantil de sua produção, retirando-a do circuito do mercado monetizado e a colocavam na dimensão de bens de subsistência que circulava na rede de parentes, vizinhos e clientes. A capacidade produtiva e o ganho dos camponeses foram dramaticamente reduzidos, numa razão inversa ao seu descontentamento.

Bissau cresceu de modo caótico. A urbanização acelerada, que já havia começado nos anos da guerra colonial, se intensificou após a independência. Muitos camponeses insatisfeitos com as políticas do PAIGC para a agricultura deixavam suas aldeias em busca do que achavam ser uma vida melhor na cidade, favorecida pelas políticas e projetos do governo. Jovens do mundo rural também deixavam suas comunidades de origem para fugir da autoridade muitas vezes sufocante dos anciãos (os cabeças dos grupos corprados de parentesco, os régulos tradicionais que ainda acumulavam bastante poder a nível local e os seniores dos grupos de idade que, associados aos primeiros, tornavam os processos de iniciação extremamente custosos, retardando a chegada dos jovens à maturidade social). Porém, uma vez chegados a Bissau, esses jovens, com pouca ou nenhuma escolarização, sem qualquer treinamento profissional que os habilitasse a entrar no mercado de trabalho da precária produção industrial ou do competitivo setor de serviços, tinham de se desenrascar improvisadamente (dubria), fazendo pequenos serviços para os novos homens grandes que surgiam numa sociedade cuja utopia tinha sido a da horizontalidade e da igualdade ou se empregando com a ajuda destes em instituições ou empresas do Estado ou em funções para as quais não tinham qualquer treinamento. Estes, por sua vez, pagavam salários baixíssimos e de modo absolutamente irregular.

E quanto mais mal se pagava e mais se atrasava os salários, mais os seus empregados reduziam a sua já baixa produtividade, se ausentando por qualquer motivo do trabalho. As doenças dos funcionários e seus familiares (o paludismo que grassava sempre forneceu uma ótima desculpa), as obrigações tradicionais (as cerimônias de iniciação e os variados ritos funerários, localmente conhecidos como tchoro) eram 
motivos culturalmente aceitos para o elevado absenteísmo. Nestes longos períodos de ausência, esses funcionários fantasmas tratavam de cuidar da vida: plantar suas hortas, voltar ao chão natal para os trabalhos agrícolas, se envolver no pequeno comércio ambulante do pouco que produziam e prestar pequenos serviços para os seus protetores. Quando nada disto adiantava, eles se voltavam para práticas ilegais de todo tipo. No início, com a ajuda de quem ainda permanecia empregado, os que estavam fora se apropriavam em pequena escala da coisa pública, alguns se envolveram com acanhados furtos nas residências dos cooperantes, mais tarde em roubos com alguma violência e, nos últimos anos, o envolvimento direto no narcotráfico e no contrabando de armas.

Após a independência, o país se beneficiou da boa vontade, inicialmente, dos países escandinavos e do Leste Europeu e, depois, de vários outros países europeus, americanos e asiáticos, que fizeram chegar à Guiné uma vultosa ajuda internacional para tocar os projetos mirabolantes de desenvolvimento e para o financiamento da máquina estatal e das redes clientelísticas que se formaram em seu entorno. A apropriação patrimonialista desses recursos e a obsessão dos dirigentes guineenses com a aquisição e exibição de bens de consumo que alocam prestígio a seus usuários (automóveis luxuosos, casas e artigos de luxo, cujo exemplo mais bem-acabado são as bebidas alcóolicas importadas) foram aos poucos detectadas pelos financiadores e doadores externos que um a um, e aos poucos, foram diminuindo essa fonte de financiamento ${ }^{20}$.

A liberalização da economia, com a consequente privatização das empresas estatais pouco efeito teve para o desenvolvimento do país. A permanente crise de abastecimento de produtos básicos certamente foi interrompida, mas o acesso aos bens de consumo primário ficou restrito à pequena parcela da população que estava integrada de fato na economia de mercado monetizada. A inflação subiu, os privilégios da classe dirigente, se não cresceram, ao menos tornaram-se mais visíveis e a exclusão dos camponeses e de uma massa de recém-chegados ao mundo crioulo se agudizou. A moeda nacional foi extinta e a Guiné passou a fazer parte da zona do Franco CFA, o que controlou a inflação, mas tornou o país mais dependente das economias maiores dos seus vizinhos, especialmente do Senegal.

Nas duas primeiras décadas após a independência, as pescas (por meio de um danoso acordo com a União Soviética) e a ajuda internacional,

${ }^{20}$ Chamado no crioulo guineense de ronku, o exibicionismo patrimonialista parece ser um atributo generalizado da cultura política na África pós-colonial, a crer na análise de Mbembe (2001). 
muitas vezes a fundo perdido, foram as maiores fontes de financiamento do Estado, que eram complementadas pela precária indústria madeireira e pela exportação de produtos agrícolas como o amendoim. O fim da União Soviética, a exaustão dos recursos pesqueiros, as constantes crises políticas que tinham como desdobramento regular a revelação do mau uso da ajuda internacional, a diminuição dessa fonte de recurso e, por fim, a inserção do país na rol dos países associados ao narcotráfico tornaram ainda mais dramática a situação econômica do país, que vive hoje uma forte dependência da exportação da castanha de caju.

\section{Balanço}

A longa lista de momentos de instabilidade política, prisões, assassinatos, intensa circulação de rumores sobre golpes tentados e conseguidos, de um lado, e de fracassos econômicos, planos e projetos frustrados, crises de abastecimento, défices orçamentais permanentes, (acusações de) corrupção, envolvimento da gente graúda com o narcotráfico e debilidade da infraestrutura e das instituições, de outro, sugerem que o balanço que agora se faz não conduz a uma direção positiva $^{21}$. Certamente, o Estado e suas instituições na Guiné-Bissau são frágeis e enfrentam desafios enormes ligados ao fortalecimento institucional e à produção de recursos humanos e materiais.

Se minha intenção nesse trabalho fosse avaliar o caminho percorrido no processo de formação estatal, minha análise poderia terminar aqui, apontando para um retumbante fracasso. Porém, minha indagação é de outra natureza. Perguntei originalmente o quanto os projetos e sonhos caros aos nacionalistas foram realmente alcançados e implementados. No coração de minha pergunta está a ideia de nação, a comunidade de sentimento que faz com que pessoas diferentes, vivendo em lugares diversos, sem laços primários de parentesco, etnia e vizinhança a os unir, se sintam parte de um todo cuja natureza é imaginada, conforme aponta o trabalho clássico de Benedict Anderson (2008). Propunha então avaliar o sucesso ou não (parcial ou pleno) do projeto crioulo para a nação. Na contemporaneidade, a forma ainda hegemônica de comunidade nacional é a que articula a nação a uma unidade política como o Estado, dando luz ao estado-nação. Por isto, passei em revista,

\footnotetext{
${ }^{21}$ Um olhar crítico para o caminho percorrido pela sociedade e pelas instituições guineenses e para o devir do país enquanto uma comunidade moral de sentimento (uma nação) já havia sido exposto por um historiador nascido e criado na Guiné por ocasião dos 30 anos de independência. Ver Amado (2005).
} 
de modo esquemático e arbitrário, alguns episódios da vida política guineense com um foco deliberado no Estado. Isto se deve ao fato de que na Guiné-Bissau o Estado precedeu a nação, sendo um importante elemento em sua construção, ao contrário do que sucedeu em Cabo Verde, onde a ideia de uma nação insular é muito anterior ao Estado cabo-verdiano.

O que está em análise aqui é o projeto crioulo (plural, insisto mais uma vez) de uma nação guineense. Vale dizer, no entanto, que meu viés antropológico faz com que eu esteja interessado na nação tal como ela é vivida pelos seus membros na sua cacofonia e heterogeneidade e não nos projetos normativos e institucionais, inscritos nos códigos legais. Estes não são alvos de minha preocupação, quem sabe a dos cientistas políticos. O retorno às origens proposto por Cabral, faria surgir uma comunidade nacional vagamente socialista, igualitária e horizontal gerou expectativa e efervescência, mas também violência e frustração. A esse projeto contrapôs-se a ideia neoliberal de nação, onde cada um poderia, por mérito e esforço próprio, alcançar o devir proposto não por si, mas pelo mercado. O resultado disto foi concentração de riqueza, desigualdade, bem como violência e frustração. Nada muito diferente do projeto rival.

Deixo esses projetos institucionais de lado e passo a tratar da nação de baixo para cima, das ideias (sempre no plural e sempre em competição) de Guiné veiculadas nas intrigas, conversas e nos rumores cotidianos. Argumentei que este projeto nacional é uma formulação da sociedade crioula para o seu devir. Através dele, ela se reproduziria de modo relativamente autônomo, se livrando da subordinação extrema a que fora submetida pelas poucas décadas de regime colonial efetivo na Guiné. Através dele, ela incorporaria uma massa de gente oriunda das sociedades indígenas em seu seio, mantendo, porém, o precário equilíbrio de forças que historicamente caracterizou as relações entre os mundos crioulo e indígena, que localizava o primeiro numa posição hierarquicamente superior ao segundo.

Como apontado anteriormente, o desafio maior da sociedade crioula guineense tem a ver com a sua pequenez e a sua incapacidade de se reproduzir somente com meios e recursos gerados em seu interior. Ela sempre teve que lançar mão de mecanismos de incorporação de gente e valores exógenos, construídos em seu exterior, nas vertentes societárias indígenas ou ibéricas, para se reproduzir ao longo do tempo. Isto fez dela uma unidade internamente diferenciada e heterogênea, sincrônica e diacronicamente. Além disto, para não se homogeneizar e 
para não perder o controle sobre as frágeis fronteiras que a separavam do mundo indígena e do universo europeu, isto é, para não se etnicizar, como ocorreu com os Krio da Serra Leoa (PORTER, 1963; SPITZER, 1974; COHEN, 1981; WYSE, 1991), ou para não se tornar uma mera elite ocidentalizada, como ocorreu com os créoles das quatro comunas senegalesas (JOHNSON, 1972; DIOUF, 1999), os mecanismos de incorporação tinham que operar num modo muito bem afinado ${ }^{22}$. Se a produção da incorporação fosse elevada demais, a fronteira com o mundo indígena se apagaria e o mundo crioulo ganharia os contornos étnicos que o aproximaria das sociedades tradicionais africanas, sendo por elas subordinado. No pólo oposto, se a incorporação ocorresse de modo muito seletivo, em baixa escala de produção, a fronteira com o mundo europeu tenderia a se apagar, tornando a sociedade crioula uma pequena elite local que agia a mando dos colonizadores europeus em tempos de calmaria ou simplesmente sufocada em tempos de competição intensa com os colonos.

Historicamente, os mecanismos de incorporação usados pela sociedade crioula eram poucos e tinham uma capacidade limitada de trazer gente para o seu interior. E quando o fazia, isto se dava de modo a criar e manter desigualdades e relações de dependência. Os principais mecanismos eram as alianças matrimoniais com os notáveis do mundo indígena, que cediam aos luso-africanos crioulizados suas filhas e irmãs em troca de lealdade e reciprocidade nas trocas comerciais. Práticas clientelísticas associadas ao comércio criavam relações de dependência mútua entre homens e mulheres crioulos e indígenas. Práticas de adoção de crianças indígenas, introjetavam nesses recém-chegados ao mundo das praças valores e saberes técnicos associados à vida europeizada. Por fim, certas formas de autoajuda inspiradas em instituições indígenas, como as manjuandadis, garantiam o funcionamento da sociabilidade na periferia crioula (TRAJANO FILHO, 2012). Com esses mecanismos de incorporação em escala apropriada, as Gãs e a elite exclusivista do fim do século XIX e início do século XX sobreviveram e se reproduziram com relativa autonomia frente aos portugueses e às sociedades indígenas. Com

\footnotetext{
${ }^{22}$ Acho por bem insistir que para se compreender as dificuldades ligadas à construção nacional, o esforço estratégico de comparação deve ser dirigido aos países vizinhos como o Senegal, a República da Guiné, a Serra Leoa e, obviamente, a Cabo Verde, e não, conforme sugerido por um parecerista, a Angola ou Moçambique. Nacionalistas e protonacionalistas de alta estirpe como os Turpin, os Pinto Bull e muitos outros tinham ligações cotidianas com esses países vizinhos. Com Angola e Moçambique os nacionalistas guineenses pouco mais compartilhavam que uma potência colonial que os tratava de modo muito diferente e algumas relações pessoais, geralmente estabelecidas em Lisboa.
} 
o advento da República em Portugal e a consequente implementação de um regime efetivamente colonial, a elite exclusivista perdeu a batalha e foi sufocada por cerca de quatro décadas pelos colonizadores, mas permaneceu heterogênea e diversificada em seu interior, o que foi $o$ germe de sua libertação.

O obstáculo maior ao pleno desenvolvimento do projeto crioulo para a nação, não se deveu, portanto, às clivagens e heterogeneidade no coração da sociedade crioula, como a que separa guineenses de caboverdianos. Estas sempre estiveram ali presentes. Mas num contexto em que as formas de identificação sempre foram múltiplas e as fronteiras entre as identidades eram um tanto tênues, ser guineense, cabo-verdiano, cristão papel, cristão de Cacheu, de Bissau ou de outra praça, civilizado, assimilado ou qualquer outra categoria identitária nunca foi um assunto do tipo tudo ou nada; sempre foi tema de negociação, discussão, reflexão, paródia, arengue e ironia.

Por isto, as tensões e as linhas de clivagem que dão forma às disputas políticas que listamos nas seções anteriores já se faziam presentes na década de 1950, quando da organização dos nacionalistas em movimentos e partidos que propunham ora a autonomia relativa, ora a independência política plena para a Guiné e Cabo Verde (separada ou conjuntamente). Na realidade, conflitos segundo essas linhas já tinham se cristalizado desde o início do século XX, quando dos movimentos protonacionalistas associados à Liga Guineense (TRAJANO FILHO, 1998). O PAIGC emergiu a partir de meados dos anos 60 como o partido hegemônico (se não único) na luta de libertação da Guiné, mas os historiadores têm revelado que, na realidade, o movimento nacionalista na Guiné foi plural, variado, prenhe de conflitos, desavenças e intrigas, produzindo alianças frequentemente efêmeras entre pessoas e grupos ${ }^{23}$. No que toca à organização das disputas, os nacionalistas guineenses agiam basicamente como membros de uma sociedade crioula que já tinha desde muito o seu kit de ferramentas próprio para gerenciar conflitos e tensões.

Durante a guerra de libertação e após a independência, os nacionalistas foram muito eficientes em mobilizar os camponeses contra os colonialistas, especialmente os balantas do sul da Guiné (RUDEBECK, 1974). A mobilização militar produziu, no entanto,

\footnotetext{
${ }^{23}$ Sobre os primórdios do movimento nacionalista na Guiner, e.(2011), Lopes (2012)uinde conflitos, desavenças e intrigas, produzindo alianças entthrow é, ver, entre outros, Chabal (1983), Dhada (1993), Nóbrega (2003), Sousa (2011), Lopes (2012) e Amado (2013).
} 
uma massa de gente que uma vez obtida a independência reivindicava ser incorporada à nação, isto é, ao mundo crioulo. Era um clamor ao qual os dirigentes não podiam fazer ouvidos moucos, pois tratava-se de gente que havia, por um lado, alcançado aos olhos de muitos o estatuto de heróis da pátria e, por outro, tinham as armas e formavam uma corporação extremamente poderosa - as FARP. Juntamente com eles, vinha a massa de jovens para Bissau em busca de educação, trabalho e libertação do poder da tradição. Em outras palavras, cresceu enormemente os candidatos à incorporação ao universo crioulizado das praças guineenses. Agregue-se a essas pressões o fato de que, durante a guerra de libertação, houve no seio do partido dirigente dramáticos processos de ascensão social e política. Jovens militantes de primeira hora do PAIGC e outros movimentos nacionalistas, saídos da periferia do mundo crioulo (como os comandantes Osvaldo Vieira, Chico Té, Nino Vieira, Domingos Ramos, Paulo Correia e lideranças controversas como Rafael Barbosa), retornaram a Bissau em 1974 como líderes do Partido, ocupando as posições mais estratégicas no governo independente, de algum modo desbancando a elite crioula tradicional ou criando a necessidade de um urgente alinhamento de forças que os reintegrasse à sociedade crioula numa nova posição ${ }^{24}$.

Para realizar todas essas enormes e urgentes tarefas, os mecanismos tradicionais de incorporação e de reprodução eram pouco mais do que precários. Eles não foram feitos para integrar e incorporar no ritmo que se fazia necessário todos os que estavam nas franjas do mundo crioulo, gente cuja reivindicação de direitos de pertencimento e de uma nova identidade já não mais se podia negar impunemente. Alianças matrimoniais estratégicas associadas à solidariedade e reciprocidade mercantil, práticas de adoção e participação em determinadas instituições de sociabilidade podiam ser eficientes no tempo das $G \tilde{a} s$ crioulas, mas já não bastavam no tempo da nação guineense. Em vez de todos esses mecanismos ou em complemento a eles, a incorporação nem sempre passou a ser feita à comunidade de sentimento que é a nação, mas a corporações organizadas em redes frouxas em contexto de grande escassez de recursos, encabeçadas pelos novos "homens grandes" que a nova cultura política produziu.

\footnotetext{
${ }^{24}$ De modo a evitar mal entendidos, ressalto que por periferia do mundo crioulo estou me referindo àquelas pessoas ou grupos que, mesmo tendo uma longa história de pertencimento às praças, viviam em situação de relativa subordinação. No sistema das Gãs, seriam os membros dos núcleos secundários, os aderentes, dependentes, clientes e auxiliares. Grosseiramete, seriam os descendentes dos grumetes do século XIX.
} 
Como acontece com muitas línguas crioulas, a sociedade crioula Guiné está se descrioulizando. Resta saber em qual direção: se rumo ao mundo africano tradicional ou em direção às formas europeizadas. Ela sempre foi pequena o bastante para ser evacuada nuns poucos voos da TAP cada vez que eclodem crises mais violentas, mas parece em certas ocasiões ser resiliente o bastante para entrar em hibernação e pouco depois retornar vigorosa, como sucedeu com os nacionalistas dos anos 50 . De uma forma ou de outra, crioula ou não, a nação está sendo construída na Guiné. O crioulo é cada vez mais a língua nacional, certas instituições de autoajuda tipicamente crioulas como as manjuandadis se fazem hoje presentes em quase todos os cantos do país, formas de sociabilidade crioulas como o carnaval também começam a ser celebradas e vividas fora das praças, o mesmo acontecendo com várias outras expressões da cultura popular. Tudo isto com o aval e a despeito do Estado.

\section{Referências}

AMADO, L. Guiné-Bissau, 30 anos de independência. In: Studia Africana, v. 8, p. 109-135, 2005.

. Guineidade \& Africanidade: Estudos, Crônicas, Ensaios e Outros Textos. Lisboa: Edições Vieira da Silva, 2013.

ANDERSON, B. Comunidades imaginadas: reflexões sobre a origem e a difusão do nacionalismo. São Paulo: Companhia das Letras, 2008.

AUSTIN, J. How to Do Things with Words. Oxford: Clarendon Press, 1962.

BARBOSA, H. Os Indígenas da Guiné Perante a Lei Portuguesa. In: Boletim Cultural da Guiné Portuguesa (BCGP), v. 6, p. 343-362, 1947.

BRITO, E. A Revogação do Estatuto dos Indígenas e o Problema da Sobrevivência dos Estatutos de Direito Provado Local nas Províncias Ultramarinas. In: $B C G P$, v. 82, p. 181-197, 1966.

BROOKS, G. Perspectives on Luso-African Commerce and Settlement in the Gambia and Guinea-Bissau Regions, 16th-19th centuries. Col. Working Papers, 24, African Studies Center. Boston: Boston University, 1980.

. Landlords \& Strangers: Ecology, Society and Trade in Western Africa, 10001650. Boulder: Westview Press, 1993.

CABRAL, A. Return to the Source: Selected Speeches. New York: Monthly Review Press, 1973.

CARDOSO, C. A Ideologia e a Prática da Colonização Portuguesa na Guiné e o seu Impacto na Estrutura Social. In: Soronda, n. 14, p. 29-63, 1992.

CASTANHEIRA, J. P. Quem mandou matar Amílcar Cabral? Lisboa: Relógio d'Água, 1995.

CHABAL, P. Amilcar Cabral: Revolutionary leadership and People's War. Cambridge: Cambridge University Press, 1983. 
COHEN, A. The Politics of Elite Culture: Explorations in the Dramaturgy of Power in a Modern African Society. Berkeley: University of California Press, 1981.

CURTIN, P. Economic Change in Precolonial Africa: Senegambia in the Era of Slave Trade. Madison: The University of Wisconsin Press, 1975.

DHADA, M. Warriors at Work: How Guinea Was Really Set Free. Niwot: University Press of Colorado, 1993.

DIOUF, M. The French colonial policy of assimilation and the civility of the Originaires of the four Communes (Senegal): a nineteenth century globalization project. In: MEYER, B.; GESCHIERE, P. (Ed.). Globalization and identity: dialectics of flow and closure. Oxford: Blackwell Publishers, 1999. p. 671-696.

DJALÓ, T. O mestiço e o Poder: Identidades, Dominações e Resistências na Guiné. Lisboa: Nova Vega, 2013.

DORJAHN, V.; FYFE, C. Landlord and Stranger: Change in Tenancy Relations in Sierra Leone. In: Jornal of African History, n. 3, v. 3, p. 391-397, 1962. http://dx.doi. org/10.1017/S0021853700003315

DUFFY, J. Portuguese Africa. Cambridge: Harvard University Press, 1959.

FORREST, J. Lineages of State Fragility: Rural Civil Society in Guinea-Bissau. Athens: Ohio University Press, 2003.

GALLI, R.; JONES, J. Guinea-Bissau: Politics, Economics and Society. London: Frances Pinter Publishers, 1987.

HOJBJERG, C. Victims and Heroes: Manding Historical Imagination in a Conflictriden Border Region (Liberia-Guinea). In: KNÖRR, J.; TRAJANO FILHO, W. (Ed.). The Powerful Presence of the Past: Integration and Conflict along the Upper Guinea Coast. Leiden: Brill Publishers, 2010. p. 273-294. http://dx.doi.org/10.1163/ ej.9789004190009.i-375.107

IGNATIEV, O. Três Tiros da PIDE: quem, porquê e como mataram Amilcar Cabral. Lisboa: Prelo Editora, 1975.

JOHNSON, G. W. The Senegalese urban elite, 1900-1945. In: CURTIN, P. D. (Ed.). Africa and the West: intellectual responses to European culture. Madison: The University of Wisconsin Press, 1972. p. 139-188.

KOPYTOFF, I. The Internal African Frontier: The Making of African Political Culture. In:. KOPYTOFF, I. (Ed.). The African Frontier: The Reproduction of Africna Societies. Bloomington: Indiana University Press, 1987. p. 3-87.

LOPES, C. A Transição Histórica na Guiné-Bissau. Bissau: INEP, 1987.

LOPES, J. V. Aristides Pereira: Minha vida, minha história. Praia: Spleen Edições, 2012.

MBEMBE, A. On the Postcolony. Berkeley: University of California Press, 2001.

MURPHY, W. Patrimonial Logic of Centrifugal Forces in Political History of the Upper Guinea Coast. In: KNÖRR, J.; TRAJANO FILHO, W. (Ed.). The Powerful Presence of the Past: Integration and Conflict along the Upper Guinea Coast. Leiden: Brill Publishers, 2010. p. 25-54. http://dx.doi.org/10.1163/ej.9789004190009.i375.15

NÓBREGA, A. A Luta pelo Poder na Guiné-Bissau. Lisboa: Instituto Superior de Ciências Sociais e Políticas, 2003. 
PEREIRA, A. O Meu Testemunho: uma luta, um partido, dois países. Lisboa: Editorial Notícias, 2003.

PORTER, A. Creoledom: A Study of the Development of Freetown Society. Oxford: Oxford University Press, 1963.

RODNEY, W. A History of the Upper Guinea Coast, 1545 to 1800. New York: Monthly Review Press, 1970.

RUDEBECK, L. Guinea-Bissau: A Sudy of Political Mobilization. Uppsala: Scandinavian Institute of African Studies, 1974.

SARRÓ, R. Map and Territory: The Politics of Place and Autochthony among the Baga Sitem (an their Neighbours). In: KNÖRR, J.; TRAJANO FILHO, W. (Ed.). The Powerful Presence of the Past: Integration and Conflict along the Upper Guinea Coast. Leiden: Brill Publishers, 2010. p. 229-252. http://dx.doi.org/10.1163/ ej.9789004190009.i-375.88

SILVA, A. E. D. A Independência da Guiné-Bissau e a Descolonização Portuguesa. Porto: Afrontamento, 1997. . 2010. Invenção e Construção da Guiné-Bissau. Lisboa: Almedina, 2010.

SOUSA, J. S. Amílcar Cabral: Vida e Morte de um Revolucionário Africano. Lisboa: Nova Vega, 2011.

SPITZER, L. The Creoles of Sierra Leone: responses to colonialism, 1870-1945. Madison: The University of Wisconsin Press, 1974.

TAVARES, A. Do Indigenato à Cidadania. In: BCGP, v. 8, p. 853-865, 1947.

TRAJANO FILHO, W. Rumores: uma narrativa da nação. In: Série Antropologia, Brasília, Universidade de Brasília, n. 143, p. 1-54, 1993.

. Polymorphic Creoledom: The "Creole" Soxiety of Guinea-Bissau. Tese (Doutorado) - University of Pennsylvania, 1998.

. Narratives of national identity in the Web. In: Etnográfica, v. 6, n. 1, p. 141-158, 2002.

. A Crioulização na Guiné-Bissau: um caso singular. In: Estudos Afro-Asiáticos, v. 27, p. 57-102, 2005a.

. A construção da Nação e o Fim dos Projetos Crioulos: Os Casos de Cabo $\overline{\text { Verde e }}$ da Guiné-Bissau. In: CRUZ E SILVA, T.; ARAÚJO, M. G.; CARDOSO, C. (Org.). 'Lusofonia' em África: História, Democracia e Integração Africana. Dakar: CODESRIA, 2005b.

. O precário equilíbrio entre improvisação e regras: reflexões sobre a cultura política da Guiné-Bissau. In: Revista de Antropologia, v. 51, n. 1, p. 233-266, 2008.

. The Creole Idea of Nation and its Predicaments: The Case of Guinea-Bissau. In: KNÖRR, J.; TRAJANO FILHO, W. (Ed.). The Powerful Presence of the Past: Integration and Conflict along the Upper Guinea Coast. Leiden: Brill Publishers, 2010. p. 155-184. http://dx.doi.org/10.1163/ej.9789004190009.i-375.59

. Território e idade: ancoradouros do pertencimento nas manjuandadis da GuinéBissau. In: TRAJANO FILHO, W. (Org.). Lugares, Pessoas e Grupos: as lógicas do pertencimento em perspectiva internacional. Brasília: ABA Publicações, 2012. p. 225-255. 
. Dentro e fora de casa: o pendular jogo de imagens da África em Cabo Verde. In: MOTTA, A.; LOBO, A.; TRAJANO FILHO, W. (Org.). África fora de Casa: Imagens fora de lugar. Recife: Aba Publicações/Editora UFPE, 2014. p. 19-61.

WYSE, A. The Krio of Sierra Leone: An Interpretative History. Washington: Howard University Press, 1991.

AMADO, L. Guiné-Bissau, 30 anos de independência. In: Studia Africana, v. 8, p. 109-135, 2005.

. Guineidade \& Africanidade: Estudos, Crônicas, Ensaios e Outros Textos. Lisboa: Edições Vieira da Silva, 2013.

ANDERSON, B. Comunidades imaginadas: reflexões sobre a origem e a difusão do nacionalismo. São Paulo: Companhia das Letras, 2008.

AUSTIN, J. How to Do Things with Words. Oxford: Clarendon Press, 1962.

BARBOSA, H. Os Indígenas da Guiné Perante a Lei Portuguesa. In: Boletim Cultural da Guiné Portuguesa (BCGP), v. 6, p. 343-362, 1947.

BRITO, E. A Revogação do Estatuto dos Indígenas e o Problema da Sobrevivência dos Estatutos de Direito Provado Local nas Províncias Ultramarinas. In: $B C G P$, v. 82, p. 181-197, 1966.

BROOKS, G. Perspectives on Luso-African Commerce and Settlement in the Gambia and Guinea-Bissau Regions, 16th-19th centuries. African Studies Center. Boston: Boston University, 1980. (Col. Working Papers, 24).

. Landlords \& Strangers: Ecology, Society and Trade in Western Africa, 10001650. Boulder: Westview Press, 1993.

CABRAL, A. Return to the Source: Selected Speeches. New York: Monthly Review Press, 1973.

CARDOSO, C. A Ideologia e a Prática da Colonização Portuguesa na Guiné e o seu Impacto na Estrutura Social. In: Soronda, n. 14, p. 29-63, 1992.

CASTANHEIRA, J. P. Quem mandou matar Amílcar Cabral? Lisboa: Relógio d'Água, 1995.

CHABAL, P. Amilcar Cabral: Revolutionary leadership and People's War. Cambridge: Cambridge University Press, 1983.

COHEN, A. The Politics of Elite Culture: Explorations in the Dramaturgy of Power in a Modern African Society. Berkeley: University of California Press, 1981.

CURTIN, P. Economic Change in Precolonial Africa: Senegambia in the Era of Slave Trade. Madison: The University of Wisconsin Press, 1975.

DHADA, M. Warriors at Work: How Guinea Was Really Set Free. Niwot: University Press of Colorado, 1993.

DIOUF, M. The French colonial policy of assimilation and the civility of the Originaires of the four Communes (Senegal): a nineteenth century globalization project. In: MEYER, B.; GESCHIERE, P. (Ed.). Globalization and identity: dialectics of flow and closure. Oxford: Blackwell Publishers, 1999. p. 671-696.

DJALÓ, T. O mestiço e o Poder: Identidades, Dominações e Resistências na Guiné. Lisboa: Nova Vega, 2013. 
DORJAHN, V.; FYFE, C. Landlord and Stranger: Change in Tenancy Relations in Sierra Leone. In: Jornal of African History, v. 3, n. 3, p. 391-397, 1962. http://dx.doi. org/10.1017/S0021853700003315

DUFFY, J. Portuguese Africa. Cambridge: Harvard University Press, 1959.

FORREST, J. Lineages of State Fragility: Rural Civil Society in Guinea-Bissau. Athens: Ohio University Press, 2003.

GALLI, R.; JONES, J. Guinea-Bissau: Politics, Economics and Society. London: Frances Pinter Publishers, 1987.

HOJBJERG, C. Victims and Heroes: Manding Historical Imagination in a Conflictriden Border Region (Liberia-Guinea). In: KNÖRR, J.; TRAJANO FILHO, W. (Ed.). The Powerful Presence of the Past: Integration and Conflict along the Upper Guinea Coast. Leiden: Brill Publishers, 2010. p. 273-294. http://dx.doi.org/10.1163/ ej.9789004190009.i-375.107

IGNATIEV, O. Três Tiros da PIDE: quem, porquê e como mataram Amilcar Cabral. Lisboa: Prelo Editora, 1975.

JOHNSON, G. W. The Senegalese urban elite, 1900-1945. In: CURTIN, P. D. (Ed.). Africa and the West: intellectual responses to European culture. Madison: The University of Wisconsin Press, 1972. p. 139-188.

KOPYTOFF, I. The Internal African Frontier: The Making of African Political Culture. In:. KOPYTOFF, I. (Ed.). The African Frontier: The Reproduction of Africna Societies. Bloomington: Indiana University Press, 1987. p. 3-87.

LOPES, C. A Transição Histórica na Guiné-Bissau. Bissau: INEP, 1987.

LOPES, J. V. Aristides Pereira: Minha vida, minha história. Praia: Spleen Edições, 2012.

MBEMBE, A. On the Postcolony. Berkeley: University of California Press, 2001.

MURPHY, W. Patrimonial Logic of Centrifugal Forces in Political History of the Upper Guinea Coast. In: KNÖRR, J.; TRAJANO FILHO, W. (Ed.). The Powerful Presence of the Past: Integration and Conflict along the Upper Guinea Coast. Leiden: Brill Publishers, 2010. p. 25-54. http://dx.doi.org/10.1163/ej.9789004190009.i-375.15

NÓBREGA, A. A Luta pelo Poder na Guiné-Bissau. Lisboa: Instituto Superior de Ciências Sociais e Políticas, 2003.

PEREIRA, A. O Meu Testemunho: uma luta, um partido, dois países. Lisboa: Editorial Notícias, 2003.

PORTER, A. Creoledom: A Study of the Development of Freetown Society. Oxford: Oxford University Press, 1963.

RODNEY, W. A History of the Upper Guinea Coast, 1545 to 1800. New York: Monthly Review Press, 1970.

RUDEBECK, L. Guinea-Bissau: A Sudy of Political Mobilization. Uppsala: Scandinavian Institute of African Studies, 1974.

SARRÓ, R. Map and Territory: The Politics of Place and Autochthony among the Baga Sitem (an their Neighbours). In: KNÖRR, J.; TRAJANO FILHO, W. (Ed.). The Powerful Presence of the Past: Integration and Conflict along the Upper Guinea Coast. Leiden: Brill Publishers, 2010. p. 229-252. http://dx.doi.org/10.1163/ej.9789004190009.i-375.88

SILVA, A. E. D. A Independência da Guiné-Bissau e a Descolonização Portuguesa. Porto: Afrontamento, 1997. 
. 2010. Invenção e Construção da Guiné-Bissau. Lisboa: Almedina, 2010.

SOUSA, J. S. Amílcar Cabral: Vida e Morte de um Revolucionário Africano. Lisboa: Nova Vega, 2011.

SPITZER, L. The Creoles of Sierra Leone: responses to colonialism, 1870-1945. Madison: The University of Wisconsin Press, 1974.

TAVARES, A. Do Indigenato à Cidadania. In: BCGP. v. 8, p. 853-865, 1947.

TRAJANO FILHO, W. Rumores: uma narrativa da nação. In: Série Antropologia, Brasília, Universidade de Brasília, n. 143, p. 1-54, 1993.

. Polymorphic Creoledom: The "Creole" Soxiety of Guinea-Bissau. Tese (Doutorado) - University of Pennsylvania, 1998.

. Narratives of national identity in the Web. In: Etnográfica, v. 6, n. 1, p. 141-158, 2002.

. A Crioulização na Guiné-Bissau: um caso singular. In: Estudos Afro-Asiáticos. v. 27, p. 57-102, 2005a.

. A construção da Nação e o Fim dos Projetos Crioulos: Os Casos de Cabo $\overline{\text { Verde e }}$ da Guiné-Bissau. In: CRUZ E SILVA, T.; ARAÚJO, M. G.; CARDOSO, C. (Org.). 'Lusofonia' em África: História, Democracia e Integração Africana. Dakar: CODESRIA, 2005b.

. O precário equilíbrio entre improvisação e regras: reflexões sobre a cultura $\overline{\text { política }}$ da Guiné-Bissau. In: Revista de Antropologia, v. 51, n. 1, p. 233-266, 2008.

. The Creole Idea of Nation and its Predicaments: The Case of Guinea-Bissau. In: KNÖRR, J.; TRAJANO FILHO, W. (Ed.). The Powerful Presence of the Past: Integration and Conflict along the Upper Guinea Coast. Leiden: Brill Publishers, 2010. p. 155-184. http://dx.doi.org/10.1163/ej.9789004190009.i-375.59

. Território e idade: ancoradouros do pertencimento nas manjuandadis da GuinéBissau. In: TRAJANO FILHO, W. (Org.). Lugares, Pessoas e Grupos: as lógicas do pertencimento em perspectiva internacional. Brasília: ABA Publicações, 2012. p. 225-255.

. Dentro e fora de casa: o pendular jogo de imagens da África em Cabo Verde. In: MOTTA, A.; LOBO, A.; TRAJANO FILHO, W. (Org.). África fora de Casa: Imagens fora de lugar. Recife: Aba Publicações/Editora UFPE, 2014. p. 19-61.

Recebido: 06 de janeiro de 2016

Aprovado: 20 de abril de 2016

\footnotetext{
Autor/Author:

WILSON TRAJANO FILHO <wilson.trajanofilho@gmail.com>

- Professor do departamento de Antropologia da Universidade de Brasília e investigador associado ao Max Planck Institute for Social Anthropology, Halle/Saale (Alemanha). Bacharel em Música pela Universidade de Brasília, mestre em Antropologia pela Universidade de Brasília e doutor em Antropologia pela University of Pennsylvania. Pesquisa de campo na área da Antropologia da África, com ênfase nos seguintes temas: história do colonialismo português em África, formação e reprodução das sociedades crioulas na Alta Costa da Guiné, cultura popular e análise de rituais e formas narrativas em sociedades africanas.

- Professor of the Anthropology Department at the Universidade de Brasilia and associate researcher at the Max-Planck-Institute for Social Anthropology, Halle/Saale (Germany). Bachelor of Music from the University of Brasilia, MA in Anthropology from the University of Brasilia and $\mathrm{PhD}$ in Anthropology from the University of Pennsylvania. Research in the field of Anthropology of Africa, with emphasis on the following topics: History of Portuguese colonialism in Africa, creole societies in Upper Guinea Coast, popular culture and analysis of ritual and narrative forms in African societies.
} 